\title{
0 JEITO CARIOCA DE SER, UM PATRIMÔNIO CULTURAL INTANGÍVEL? ARQUEOLOGIA DOS SENTIDOS DE UMA CIDADE
}

Phrygia Arruda (UFRJ)

O artigo prioriza quatro ilustres escritores que publicaram crônicas na Gazeta de Notícias e apresentaram uma visão da realidade social, ou melhor, uma representação de práticas intelectuais da vida carioca. O que podemos reconhecer nessas crônicas é um olhar crítico e irônico sobre o modo de ser e agir do povo carioca da Primeira República aos anos 30 do século XX. O texto dá prosseguimento à pesquisa teórica que examinou subjetividade particular, singularizada numa população, numa cultura e numa mentalidade imersas na malandragem, no erótico e no lazer, origem da construção de um imaginário "jeito carioca de ser". Considerando esse jeito um bem cultural, de acordo com o decreto 3.550, nos constituímos como patrimônio cultural brasileiro de natureza imaterial. Segundo os cronistas a cidade do Rio de Janeiro é depositária fiel desse jeito carioca de ser, fruto de criações imaginárias, portanto imateriais, cuja existência está profundamente enraizada em toda vida material e imaterial de hoje e de tempos passados.

\section{JEITO CARIOCA, PATRIMÔNIO IMATERIAL, RIO DE JANEIRO, MEMÓRIA COLETIVA.}

ARRUDA, Phrygia. O jeito carioca de ser, um patrimônio cultural intangível? arqueologia dos sentidos de uma cidade. Textos escolhidos de cultura e arte populares, Rio de Janeiro, v.9, n.2, p. 159169, nov. 2012. 


\section{THE CARIOCA WAY OF BEING,}

\section{AN INTANGIBLE CULTURAL HERITAGE? \\ THE ARCHAEOLOGY OF THE SENSES OF A CITY}

Phrygia Arruda (UFRJ)

The article concentrates on four distinguished writers who published short stories in the Gazeta de Notícias and presented a vision of social reality, or rather a representation of intellectual practices of life in Rio. What can be recognized in these stories is a critical and ironic account of the way of being and acting of Cariocas from the First Republic to the 1930s. The text gives continuity to the theoretical research that examined particular subjectivity singularized in a population, a culture and a mindset immersed in trickery, eroticism and leisure, starting points of the "carioca way of being". Considering this a cultural asset, in accordance with Decree 3550, we constitute ourselves as Brazilian cultural heritage of immaterial nature. According to the writers, the city of Rio de Janeiro is a faithful depository of the Carioca way of being, a result of imaginary creations, whose existence is deeply rooted in the whole material and immaterial life of today and of the past.

CARIOCA WAY, INTANGIBLE ASSETS, RIO DE JANEIRO, COLLECTIVE MEMORY.

ARRUDA, Phrygia. O jeito carioca de ser, um patrimônio cultural intangível? arqueologia dos sentidos de uma cidade. Textos escolhidos de cultura e arte populares, Rio de Janeiro, v.10, n.2, p. 159-169, nov. 2013. 
Amar o perdido/deixa confundido/este coração./Nada pode o olvido/contra o sem sentido / do apelo do Não./As coisas tangíveis/ tornam-se insensíveis/à palma da mão. Mas as coisas findas,/muito mais que lindas/essas ficarão (CARLOS DRUMOND DE ANDRADE, "Memória").

\section{INTRODUÇÃO}

Neste artigo $^{1}$ discutimos o jeito carioca de ser como patrimônio cultural imaterial, trabalhando com textos que poderiam responder à questão do título, ou seja, a relação possível entre patrimônio cultural intangível e a formação de uma subjetividade local. Tal discussão, porém, remeteu à questão que se busca compreender sobre a relação entre memória, categoria fundamental na área de patrimônio cultural, e a psicologia enquanto área que estuda as "subjetividades contemporâneas" que evocam relações conflitantes e de tensões entre o que se mantém pela tradição e o que se modifica e se moderniza. Assim, o "jeito carioca de ser", neste artigo, tem como referência as crônicas de Machado de Assis, Olavo Bilac, João do Rio e Lima Barreto, publicadas na Gazeta de Notícias, entre 1890 e 1930, apresentando uma visão da realidade social, ou melhor, uma representação de práticas intelectuais da vida carioca.

Na pesquisa original agora retomada tratamos da realidade intangível que tem como referência a maneira de ser dos cariocas e a paisagem sociocultural e política da cidade do Rio de Janeiro, tendo como suportes narrativas tanto pessoais quanto da mídia escrita - mais precisamente jornais, crônicas e revistas de diferentes épocas que descreveram o cotidiano da cidade.

\section{FOLHETIM, JORNAL E CRÔNICAS}

Desde o período joanino até o início do século XX, quando vimos estudando o Rio de Janeiro nos deparamos com diferentes assuntos que ligavam o jeito carioca ao da cidade e ao modernismo nascente. Modernismo esse que, na Europa e mesmo no Brasil e por extensão no Rio de Janeiro, vinculava-se às artes, à literatura, ao cinema, à rádio, à televisão e aos jornais, enfim à vida cultural da sociedade carioca; chegamos assim aos cronistas que escreveram e descreveram o cotidiano da cidade e do carioca.

No Rio de Janeiro, a produção dos caricaturistas e dos cronistas mostrava-se particularmente rica como registro da cultura da cotidianidade. Fazendo do tempo sua matéria-prima, a crônica constitui-se em fonte indispensável para a reflexão historiográfica. Ao analisar o papel da crônica na história, Neves (2000) ressaltou a força da subjetividade como dimensão que 
dá sentido à própria constituição da história. É através de comentários, ideias, impressões ou dos traços risíveis de uma caricatura que a crônica singulariza os acontecimentos, dando-Ihes feição e interpretação muito próprias.

É importante dizer que o legado do romantismo literário brasileiro foi bastante fecundo, dos mais relevantes, de excelente nível em alguns casos, e se relaciona com o folhetim, a crônica e o jornal.

O folhetim foi introduzido no Brasil com o Romantismo, importado da França, segundo Castello (1999), definido como textos curtos publicados no rodapé da página de maior destaque do jornal, narrativas ficcionais capítulo por capítulo, no dia a dia ou semanalmente. Tal produção literária era imediatamente difundida, o que acabou ampliando a função jornalística da época - mais precisamente, do final do século XIX.

Aspecto distinto e interessante do folhetim é sua leitura ter feito parte dos costumes da época, principalmente, dos saraus familiares. Tem-se, por exemplo, o escritor José de Alencar, um dos primeiros e principais cultores desse gênero literário, que numa crônica relatou a experiência como ledor nos saraus junto a seus familiares.

Outro aspecto relevante é que o jornal apelava para o folhetim (MEYER, 2005) como recurso para prender a atenção de seus leitores, através de explicações rápidas ou referenciais de situações anteriores, encadeadas às seguintes. A versatilidade e a heterogeneidade do conteúdo desse gênero literário nascente são ressaltadas, já que os textos atravessavam diversos acontecimentos, passando do gracejo ao assunto sério, do riso e do prazer às misérias e às chagas da sociedade, e tudo isso com graça, finura e delicadeza.

O folhetim era também designado como crônica e revista, associado ao adjetivo hebdomadário, nesse caso indicativo do ritmo semanal de coleta da matéria e de sua divulgação pela imprensa. A crônica apresenta íntima relação com a narrativa ficcional e o teatro, que lhe oferece rica matéria social, também política e mesmo econômica, nos limites de época em que se situa. Há ainda os aspectos da linguagem, cujo exercício contínuo visava à graça, ao humor, à leveza da crítica e da caricatura, ao diálogo com o leitor. Contribuiu consideravelmente para a diferenciação e conquista de nossa linguagem literária, além de refletir, com o tempo, forte conteúdo lírico. Para explicar a crônica como método de análise, é preciso, inicialmente, discutir os termos modernidade e cidade.

Também o Rio de Janeiro do começo do século XX foi sendo modificado na esteira da modernidade, e acabou tornando-se o emblema das metamorfoses no Brasil. Apesar de o Rio de Janeiro do final do século XIX ter 
sido um caos, a cidade, já na primeira década do seguinte, é outra, mas suas mudanças, diferentemente das de Paris, onde o alargamento dos espaços tinha aspectos políticos explícitos, eram fortemente de caráter saneador.

\section{METODOLOGIA}

Objetivando novas fontes de informações da realidade pesquisada - o jeito carioca de ser - usamos como método a técnica da indexação das crônicas inicialmente publicadas na Gazeta de Notícias buscando atender aos objetivos iniciais da pesquisa, de salvaguardar e de preservar a diversidade cultural dos sujeitos cariocas e do Rio de Janeiro.

Quando Benjamin (1992), no texto O Narrador, critica o desaparecimento das narrativas, enxergamos nas crônicas um substituto da revitalização de uma tradição oral, mas, principalmente a possibilidade de ter um a mais daquilo que foi escrito. São narrativas de diferentes cronistas do final do século XIX até os anos 40 do seguinte que traçaram um perfil de uma identidade cultural - a do carioca.

Sobre a crônica propriamente dita, vários foram os textos pesquisados, que enfatizavam a importância, sobretudo da imprensa na cidade, em especial o surgimento da Gazeta de Notícias. A partir da expansão e modernização da imprensa, em meados do século XIX, os diários, na então capital federal, são responsáveis por uma imprensa mais liberal, com a publicação de textos curtos e leves, voltados para o cotidiano. Não há repúdio à modernidade dos países europeus; ao contrário, nossa cidade de alguma maneira buscou mimetizar a Paris desse período.

A crônica foi, inicialmente, tida como descrição impressionista e efêmera dos fatos em que o cronista narrava sua visão do mundo que o cercava, e segundo Borges (2001, p. 35) "há entre o Rio de Janeiro e a crônica tal afinidade que chega a ser difícil fazer a história da cidade sem se evocar os cronistas que dela falaram".

Apesar das críticas como gênero literário, a crônica imprime em seus relatos temas, que levam à compreensão da produção cultural material e imaterial da vida nacional. Tem relação com os acontecimentos cotidianos, usando linguagem descontraída, despojada de artificialismos, e induz à intimidade, pelo tom de cumplicidade com o leitor e humor prazeroso frente à realidade imediata. A matéria-prima da crônica é o tempo, envolvida com as perspectivas política, social e cultural dominantes de cada época. 


\section{OS CRONISTAS}

O fato de ter escolhido a princípio quatro ilustres escritores, como Machado de Assis, Olavo Bilac, João do Rio e Lima Barreto, que publicaram crônicas na Gazeta de Notícias, nos permite apresentar uma visão parcial da realidade social, ou melhor, uma representação de práticas intelectuais da vida carioca. Não levamos em conta as outras representações do social, isto é, as práticas de distintos grupos populares; contudo, excetuando Lima Barreto, vítima de grande preconceito por sua condição social e racial, esses escritores estavam inseridos na cidade culta, e todos tinham uma visão crítica dos acontecimentos políticos e sociais, que deve ser considerada.

O que podemos reconhecer nas crônicas até então analisadas é um olhar crítico e irônico, ressaltado no modo de ser e agir do povo carioca da Primeira República aos anos 30 do século XX. Em época marcada pela recém-implantação do sistema republicano, os cronistas algumas vezes cobram dos habitantes da cidade certo posicionamento político, sobretudo em dias de eleições, e nos apresentam as importâncias histórica, cultural e política da então capital federal.

Junto com os primeiros romances de enredos provincianos e conservadores, entre 1872 e 1878, o tratamento da matéria brasileira através das crônicas vai adensando seu ceticismo. Foram mais de 700 escritas durante quase 40 anos, com intervalos e pseudônimos, como era costume. ${ }^{2}$

Machado de Assis na crônica de 22 de janeiro de 1893, observa que o Rio de Janeiro é uma capital "obra dos tempos", "filha da história", e que é importante os cariocas se darem conta da permanência das paisagens e construções como bens materiais, assim como da permanência dos acontecimentos da vida pública da cidade como bens imateriais e dos quais, aliás, pouco ou nada participam, ressaltando a nós, leitores, características de um povo apático politicamente e descrente do poder público, fato que, vale dizer, se verifica também nos dias de hoje.

Nessa crônica é visível o que Machado se propôs quando escreveu em 1862, em $O$ Futuro sobre a sua pena de cronista seguindo as regras assim descritas: não se meter em assuntos de política ou de outras origens, mas dar ênfase aos fatos mínimos que vão desembocando por associação em outros, que surgem na mente do escritor.

Contudo, ao iniciar a crônica tratando das atrizes e de seus serviços artísticos, ele dá voz à maneira como as atrizes eram vistas (malvistas) na sociedade carioca de então, incluindo favores oferecidos além do espetáculo; logo emendando com o centenário de Tiradentes, embora elevando o alferes a 
patriota, no final faz um chiste com seu nome e sua alcunha, dando a impressão de que naquele tempo de pompa e circunstância era importante, para não cair no ridículo, possuir nome de família reconhecido socialmente; a alcunha de Tiradentes [arrancar dentes], entretanto, gerava cognome depreciativo, não sendo doutor, mas um mero arrancador de dentes, um sangrador.

Sobre a eleição, esta, me parece, faz parte da lógica do que importava naquele tempo - quais eram as prioridades da sociedade? Machado busca ironizar os fatos que seriam importantes e os trata de maneira jocosa.

Ao final, devemos nos perguntar qual era o problema focalizado: não será de uma sociedade ambivalente diante dos acontecimentos, principalmente das pessoas, que podem ser vistas ou malvistas de acordo com os ofícios que exercem e com o modo como esses ofícios são considerados pela sociedade daquela época.

Como se observa na indexação dessa crônica, poucos adjetivos definem o Rio de Janeiro; contudo, parece haver um paralelo entre a cidade e o jeito carioca. O verso final descreve o movimento da crônica de Machado, cujos temas parecem ter a cadência do balançar de uma rede - indo e vindo, indolentemente, de um assunto a outro. balançando indolentemente "... Sara, belle d'indolence, Se balance dans un hamac...3".

Podemos afirmar que, para Machado de Assis, as características mais relevantes do jeito dos cariocas eram: ser comemorativo, descompromissado, politicamente apático e descrente. E as características mais relevantes da cidade ser festeira, politicamente pouco calorosa, berço da intelectualidade e da preguiça - estavam em sintonia com sua população.

Olavo Bilac em 1897 já colaborava como cronista na Gazeta de Notícias (1890), chamado a substituir Machado de Assis. Eram tempos de grandes modificações políticas e sociais na cidade do Rio de Janeiro, e também nesse jornal, que passa a apostar na colaboração literária no Brasil. As crônicas de Bilac (1896-1903) vinham na primeira página também, mas do lado direito da folha e, às vezes, terminavam na segunda página. Eram assinadas no final, por suas iniciais (O.B.).

"Somos maometanos", em Vossa Insolência (BILAC, 1996), é sua última colaboração na Gazeta de Notícias (10.4.1904), e ele se despede informando que suas crônicas agora não serão mais uma resenha da vida carioca porque está indo para a Europa de onde escreverá sobre aspectos da vida estrangeira, de outros climas e de outras gentes. 
Nesse texto Bilac faz um jogo entre a cidade e a gente carioca, pois se as coisas melhoram são obras do acaso, mas se pioram a responsabilidade é do serviço público, do governo. Faz também algumas observações sobre o jeito de ser do povo carioca: supersticioso, descrente, mas, por outro lado, acredita no amanhã. Os acontecimentos são obra do acaso e não da força do trabalho, mesmo quando são perceptíveis as melhorias na cidade.

João do Rio (1909, p. 121), na crônica “O dito da rua", nos demonstra um vício de linguagem comum à época e que traduz um jeito malandro de ser carioca, a tentativa do "se dar bem" anseio de todo bom malandro carioca: "Há agora pelas ruas da cidade um novo dito da população. Esse dito é ouvido em cada canto e não exprime particularmente cousa alguma. É antes uma das mil faces da irreverência arrogante do canalha. O malandro para, ginga, diz mordaz: 'E eu, nada?'”.

O autor acrescenta ainda outros ditos comuns aos malandros:

Se vem alguém com conversas e "presepadas", o malandro chupa o cigarro, balança o corpo e tem três frases, que são como reIhadas. A primeira é a de deboche: 'Talvez te escreva...'. A segunda acentua-o: 'Não me venhas de borzeguins ao leito.' A terceira é mais grave: 'Não sei ler, meu chefe.' É definitivo. Não vai, não quer compreender. A imagem é de uma evidência absoluta. $E$, quando o outro se encoleriza, estas três palavras: "Suspenda o prato..." (p. 124).

De imediato, o autor nos relaciona tal atitude do malandro às características da própria cidade, atentando-nos para o fato de que o malandro carioca é, ainda, extensão da própria cidade do Rio de Janeiro: “Com meia dúzia de ditos de rua constrói-se o malandro carioca" (p. 124).

Lima Barreto na crônica "Pólvora e cocaína", de 5.1.1915 traz temas políticos e as políticas contraditórias, mas, apesar de o cronista não se referir ao povo, enxergamos em suas crônicas aspectos que poderíamos considerar dos habitantes da cidade - do carioca: explosivo, permissivo, contraditório e viciado. Há também ênfase nos noticiários dos jornais que publicam notícias explosivas, escandalosas, mas parece não tomar partido a favor dos cidadãos. Na crônica, de maneira jocosa, menciona uma cidade dividida entre o subúrbio e o outro lado, que ele não especifica. No subúrbio a vida é mais tranquila, pode-se andar à noite nas ruas sem sofrer nenhum constrangimento; além disso, critica os jornais que tendem a conferir ao subúrbio um viver mais perigoso, que necessita de polícia acordada e atenta. Novamente, vemos o escritor, ao enfocar o mundo do subúrbio carioca, apontar para outro cotidiano. 
Como em todas as suas crônicas, propõe olhar a cidade por outra perspectiva, que busca ressignificar seus fatos e os personagens do cotidiano. A cidade e a falta de preocupação das autoridades com ela são os pontos-chave dessa crônica, pois, procurando modernizar o Rio, preocupados em transformálo numa metrópole, ao modelo da Belle Époque europeia, seus administradores se esquecem de olhar para a cidade real. Com relação ao jeito de seus cidadãos, os cariocas aparecem como sujeitos pouco preocupados com o essencial e inquietos com o exterior.

As crônicas de Lima Barreto, escritor de grande importância no período pré-modernista, vítima de forte preconceito social e racial, segundo Santos (2004), adepto de estilo e linguagem simples e coloquiais, estabelecem, assim, mais contato com o povo.

Destaca-se o autor por denunciar injustiças, desigualdades sociais e preconceitos presentes no país, que podemos destacar como um jeito solidário do carioca, de reclamar, mas também de comportamentos que denotam convívio mais solidário e íntimo entre vizinhos, tão diferentes dos apregoados pelas sociedades capitalistas modernas. Segundo Santos (2004, p. 29) apesar de tamanha produção, a recepção crítica de suas obras em vida foi marcada por instabilidade que registrava ora elogios entusiásticos, ora censura e depreciação ou, o que é pior, o silêncio.

\section{CONSIDERAÇÕES FINAIS}

A cidade do Rio de Janeiro sempre foi referência de um Brasil moderno e, apesar de tudo e de muitos, ainda segue conservando sua aura de capital cultural do país. Qual é o patrimônio cultural expressivo que a cidade do Rio de Janeiro nos legou? Quais memórias da cidade se estão perdendo?

No dizer de Dodebei (2005, p. 49), a memória social, pode ser construída na dimensão da oralidade e também nas dimensões da escrita e da imagética, já que toma, na atualidade, o modelo de sociedade complexa, diversificada e heterogênea (sociedade urbana plural) que contempla as relações entre memória e projeto, e sua importância para a constituição de identidade.

Sendo assim, é possível dizer que o jeito carioca de ser brevemente aqui descrito pelos cronistas se encontra em meio à tradição e nos constituiu como sujeitos parte de uma cidade e da modernidade que, ao se instalar, apenas reforçou um jeito com a marca de uma mentalidade curiosa, aberta às novidades que os tempos modernos iam produzindo, e determinou o imaginário do Brasil moderno. 
Se pudermos considerar o jeito carioca de ser um bem cultural, que no seu conjunto é portador de uma referência, tem identidade legível, com maneiras próprias e identificáveis de viver, com criações, principalmente artístico-culturais com valor histórico, então, de acordo com o decreto $3.550^{5}$, o carioca de qualquer localidade, nascido na cidade ou não, nacional ou estrangeiro constitui patrimônio cultural brasileiro de natureza imaterial.

Nesse sentido, quando o decreto dispõe sobre o registro de bens culturais de natureza imaterial, o jeito carioca de ser deve constar registrado no Livro dos Saberes, no das Celebrações, do das Formas de Expressão e, como previsto, num Livro dos Imaginários Sociais e Culturais. E deve-se observar que a cidade do Rio de Janeiro é depositária fiel desse jeito carioca de ser, fruto de criações imaginárias, portanto imateriais, e que sua existência está profundamente enraizada em toda a vida material e imaterial de hoje e de tempos passados. E é este o patrimônio que esta cidade, tão generosa, deixa como legado a todos: suas paisagens, sua arquitetura e, principalmente, seu povo, espontâneo, descontraído, irreverente, que apesar de todas as adversidades é alegre, sempre com tempo para "dar um mergulho" na praia.

É preciso, contudo, que habitantes, governantes e principalmente os órgãos oficiais de preservação se juntem em defesa da cidade do Rio de Janeiro, para que ela não venha a ter seus patrimônios cultural imaterial e natural descaracterizados, em nome da indústria do entretenimento e da democracia.

Durante estes últimos dez anos nos dedicamos a estudar e conhecer o jeito carioca de ser, fruto de criações imaginárias de muitos; nos mais diferentes campos de ações sobre os quais nos debruçamos, porém, percebemos que há um "jeito carioca de ser" moderno ou tradicional que sobrevive na memória dos cariocas e dos brasileiros.

E ser moderno não é só viver numa grande cidade, no anonimato, com medo da violência, se escondendo nos condomínios, atrás dos muros altos, sem conviver com vizinhos que pouco se veem e moram nesses espaços fechados. Nem estar conectado à Internet. Nada disso é ser moderno, porque todo mundo está na "mesma". Ser moderno é sair correndo atrás do passado, que atua no presente, e transforma em vida nova a situação que restou da anterior.

Parafraseando Mário de Andrade, no Rio de Janeiro haveria que tombar o sentimento do carioca, seu jeito de ser e suas paisagens. 


\section{REFERÊNCIAS BIBLIOGRÁFICAS}

ASSIS, Machado de. A Semana I. São Paulo: Editora Globo, 1997.

BENJAMIN, Walter. Sobre arte, técnica, linguagem e política. Trad. Maria Luz Moita. Lisboa: Antropos. 1992.

BILAC, Olavo. Vossa insolência: crônicas. (org. Antônio Dimas). São Paulo: Companhia das Letras, 1996.

BORGES, Valdeci Rezende. Em busca do mundo exterior: sociabilidade no Rio de Machado de Assis. Estudos Históricos. Rio de Janeiro, n.28. 2001.

CASTELLO, José Aderaldo. A literatura brasileira. Origens e unidade. v 1 e 2. São Paulo: Edusp, 1999.

DODEBEI, V. Memória, circunstância e movimento. In: GONDAR, Jô e DODEBEI, Vera (orgs). O que é memória social? Rio de Janeiro: Contracapa. 2005.

MEYER, Marlyse. Folhetim/Uma história. 2. ed. São Paulo: Companhia das Letras, 2005.

NEVES, Margarida de Souza. A cidade e a paisagem. In: MARTINS, Carlos (org.). A paisagem carioca. Rio de Janeiro: Museu de Arte Moderna, Prefeitura do Rio, 2000.

RIO, João do. Cinematographo (chronicas cariocas). Lisboa: Porto editora. 1909.

SANTOS, Fábio Eliomar do Carmo Souza. Do subúrbio à neofavela: contravenções literárias e discurso em Lima Barreto e Paulo Lins. Dissertação (mestrado) Instituto de Letras da Universidade Federal Fluminense, Niterói, 2004.

\section{NOTAS}

10 texto atual é um breve resumo da pesquisa desenvolvida no estágio de pósdoutorado no Programa de Pós-Graduação em Memória Social/UNIRIO (20072008).

2 No texto usamos como exemplo uma crônica de cada um dos cronistas estudados no período 2007-2008.

3 Crônica de Machado de Assis de 22 de janeiro de 1893 (ASSIS, 1997).

4 As crônicas de Lima Barreto podem ser encontradas no site www.dominiopublico. gov.br.

50 decreto 3.551/00 de 04 de agosto de 2000 Institui o Registro de Bens Culturais de Natureza Imaterial que constituem patrimônio cultural brasileiro e cria o Programa Nacional do Patrimônio Imaterial.

Phrygia Arruda é doutora em psicologia e mestra em comunicação pela UFRJ, pós-doutora em memória social pela UNIRIO e professora-associada do Instituto de Psicologia da UFRJ. 
